\title{
Usando as tecnologias da informação no ensino de Física: o blog da Lua ${ }^{+*}$
}

Antonio Augusto Soares ${ }^{1}$

Departamento de Física, Química e Matemática

Universidade Federal de São Carlos

Renato Rodrigues Medina ${ }^{2}$

Ariovaldo Carboni ${ }^{3}$

Farley William Costa ${ }^{4}$

Mestrandos no Mestrado Nacional Profissionalizante em Ensino de Física

Departamento de Física, Química e Matemática

Universidade Federal de São Carlos

Campus Sorocaba

Sorocaba - SP

\section{Resumo}

Os recursos tecnológicos dos quais dispomos em nosso dia a dia exigem que repensemos nossas atuações enquanto professores e trabalhemos no sentido de fazer bom uso desses recursos em nossas atividades profissionais, isto é, na docência. Isso se mostra ainda mais marcante quando nos referimos ao ensino da física, principal responsável pelas bases e desenvolvimento de tais recursos. Neste trabalho apresentamos os resultados de um estudo de caso onde construímos e utilizamos um blog, com conteúdos relacionados à Lua, junto a diferentes turmas do ensino médio regular. Partindo de uma análise qualitativa das observações feitas pelos professores das turmas e de um teste aplicado aos estudantes, concluímos que

\footnotetext{
${ }^{+}$Using information technologies in Physics teaching: the moon's blog

* Recebido: dezembro de 2015.

Aceito: julho de 2016.

1 E-mail: aasoares@ufscar.br

2 E-mail: renatomedina@ hotmail.com

3 E-mail: aricarboni@gmail.com

4 E-mail: farley_costa@yahoo.com.br
} 
o uso dessa ferramenta leva a um maior protagonismo por parte dos estudantes no estudo do tema aqui abordado, contribuindo no processo ensino-aprendizagem de tópicos sobre a Lua e suas propriedades físicas.

Palavras-chave: Ensino de Física; Tecnologias da informação aplicada ao ensino; Blog.

\begin{abstract}
The technological resources that we have in our day lives make mandatory that we rethink about our actions as teachers and work in order to make a good application of those resources in our professional activities, i. e., as a teacher. This shows up in a more evident way when we refer to teaching physics, that is the major responsible by the development of those resources. In this work, we present the results about a study where we construct and used a blog with subjects about the Moon along with different secondary high school classes. Supported by a qualitative analisys of the teachers perceptions and of a test applied to the students, we concluded that using such a tool takes the students to a better protagonism in studing the subject here explored, contributing to the teaching-learning process about Moon's topics and its properties.
\end{abstract}

Keywords: Physics teaching; Information technologies applied to Education; Blog.

\title{
I. Introdução
}

Atualmente as tecnologias da informação são uma constante na vida de praticamente todas as pessoas. Nesse mundo moderno, do qual indissociavelmente fazemos parte, é difícil ficarmos alheios às melhorias e confortos advindos do desenvolvimento dos computadores pessoais, dispositivos móveis, internet de alta velocidade etc. Tais elementos, de uma forma ou de outra, são acessíveis praticamente a todos os extratos da sociedade, principalmente entre aqueles mais jovens que, em sua totalidade, já nasceram imersos nesse mundo tecnológico. É, então, bastante importante que tais tecnologias sejam, sempre que possível, utilizadas no desenvolvimento e na aplicação de novos métodos e formas de se ensinar ciência, seja no ensino fundamental (EF), no ensino médio (EM) ou no superior.

Como apontado por Vasconcelos e Leão (2012), o ensino praticado nas escolas ainda é muito distante daquilo que o indivíduo precisa conhecer para, então, desenvolver uma postura crítica diante das informações que recebe em seu dia a dia. Conforme discutido nas Diretrizes Curriculares Nacionais (BRASIL, 2013), as tecnologias da informação têm alterado o comportamento das pessoas. Assim, é mandatório que elas sejam incorporadas pelas escolas 
em seus processos de ensino, inclusive no sentido de se evitar uma nova forma de exclusão, a digital.

No que se refere ao EM, segundo os parâmetros curriculares nacionais (BRASIL, 2002),

Os conteúdos, as metodologias e as formas de avaliação serão organizados de tal forma que ao final do ensino médio o educando demonstre: I - domínio dos princípios científicos e tecnológicos que presidem a produção moderna....

Como vemos, tal documento recomenda o uso das tecnologias nos componentes curriculares. Isso indica que não podemos ignorar a forte e incontestável presença da ciência e da tecnologia no dia a dia da sociedade atual, uma vez que estas se inserem fortemente nas relações sociais e nas atividades produtivas do século XXI.

Segundo a Organização das Nações Unidas para a Educação, Ciência e Cultura (UNESCO), as Tecnologias da Informação e Comunicação (TIC) devem permitir: a universalização da educação; sua equidade; a qualidade do processo ensino-aprendizagem; o desenvolvimento do professor em sua profissão e um melhor gerenciamento educacional (UNESCO, 2015).

No que tange especificamente à física, as TIC aplicadas ao ensino devem contribuir para melhorar a compreensão de como a física transforma o mundo onde vivemos, ainda mais se considerarmos que essas tecnologias são frutos dos avanços permitidos pela própria física. Um cidadão, ciente do mundo onde vive e sensível a ele, deve ter em sua formação meios de compreender tais transformações. Assim, cabe ao professor buscar meios de utilizar e aplicar metodologias que se encaixem nesse mundo tecnológico. É necessário apresentar aos estudantes de forma clara a relação entre a física ensinada na escola e o mundo tecnológico do qual fazemos parte, assegurando um melhor protagonismo social por parte do indivíduo. Nesse sentido, Araújo e colaboradores (2012) apontam a necessidade de se desenvolver estratégias para utilizar tais tecnologias, evitando um fim em si mesmo. Tais estratégias, ainda segundo esses autores, têm que surgir no sentido de se evitar a mecanização na resolução de problemas e o simples acúmulo de informação.

Em relação aos estudantes, nativos digitais, estes já estão inseridos nesse contexto tecnológico durante seu dia a dia. Seu envolvimento com a tecnologia é natural pois nascem, crescem e se desenvolvem em um mundo tecnológico, rodeados de informação e com muita facilidade em acessá-la (PALFREY; GASSER, 2011). Desta forma, o uso das TIC aplicas ao ensino de física ocorre de maneira natural ao estudante, evidenciando a ele ampla correlação com seu dia a dia. 


\section{O blog e o ensino de Física}

Um exemplo de aplicação tecnológica que contribui para com a conexão entre a física da sala de aula e a tecnologia atual é a disponibilização e o uso de materiais didáticos na internet. Isso se configura como uma espécie de transposição didática do mundo tecnológico para as salas de aula. Essa abrangente ferramenta, a internet, é um instrumento facilitador, que permite ao professor aproximar a física ao interesse dos estudantes (FIOLHAIS; TRINDADE, 2003). Dentre as possibilidades de uso da internet, o desenvolvimento de um blog junto aos estudantes é uma das alternativas para estimular e desenvolver as competências e habilidades relacionadas ao aprendizado da física.

Alguns trabalhos têm sido realizados recentemente sobre a utilização de blogs no ensino dessa matéria. Por exemplo, Pontes e Castro (2011) realizaram um trabalho junto a professores de uma escola de EF no estado do Ceará. Avaliaram como os professores se apropriam e utilizam o blog como ferramenta em suas atividades docentes. Concluíram que é necessário que o professor conheça melhor as potencialidades dessa ferramenta pedagógica. A falta de tempo reservado para formação e planejamento das aulas também é apontada como um elemento que dificulta a apropriação dessa tecnologia por parte daqueles professores. Em outro trabalho, Leite e Carneiro (2009) apontam que o blog pode ser um recurso pedagógico utilizado para acesso a informações específicas e como espaço de disponibilização de informação por parte do professor. Eles ainda afirmam que, em uma perspectiva educativa, podem servir como portfólio digital, espaço de intercâmbio, debate e integração. Isso permite que o estudante desenvolva a capacidade de lidar com alternativas simultâneas indo, por exemplo, ao encontro da proposta de aprendizagem de Bruner (1973). Ainda no que diz respeito a trabalhos envolvendo o uso de blogs no ensino, Duda e Garret (2008) realizaram um experimento no qual promoveram o engajamento de seus estudantes em uma discussão sobre as aplicações da física no mundo real. Eles observaram que aqueles estudantes que se envolveram com o blog, ao contrário dos demais, mantiveram suas atitudes positivas em relação à física, passando a observar os assuntos abordados no blog como mais relevantes em suas vidas. Nesse sentido, vemos que o blog, quando bem utilizado no processo do ensino da física, apresenta potencial em diminuir a "distância” entre o estudante e essa ciência, tão presente em nossas vidas. Isso faz com que os tópicos relacionados à física se tornem mais relevantes aos olhos dos estudantes, podendo levar a um maior engajamento e protagonismo por parte dos mesmos.

Para Fraga e seus colaboradores (2011), o blog ainda pode ser utilizado como recurso didático que potencializa a ação pedagógica do docente que procura inovar em sua aula, proporcionando a seus estudantes maior interação com a informação. Essa tecnologia, quando aplicada adequadamente, pode transformar o processo de ensino aprendizagem, pois permite ao estudante se tornar co-autor de seu próprio aprendizado. Outro fator importante do ponto de vista do professor é que o blog permite atender àqueles estudantes que, eventualmente, tenham interesse em compreender fenômenos que estão além daqueles contidos no programa da disciplina no EM (DEL BARCO; PAREDES, 2010). 
Torres-Zúñiga (2009) desenvolveu um trabalho onde acompanhou, durante 2 anos consecutivos, a utilização de um blog intitulado "El Tao de la Física" com temas relacionados à física. Além de apresentar e discutir a estrutura básica do blog acima referido, nesse trabalho é feita uma análise estatística do acesso ao blog no período em questão. $\mathrm{O}$ autor conclui que o blog é uma ferramenta que permite de forma simples publicar informações que complementem o conteúdo trabalhado nas aulas. Outro aspecto que o autor cita é o caráter popularizador da ciência apresentado pelo blog.

De acordo com Pietrocola (2006), é necessário que se articule o saber novo com o antigo. Nesse sentido, o uso de blogs, pode se caracterizar como uma ferramenta importante se bem explorada pelo professor junto aos estudantes que, por sua vez, já apresentam certo conhecimento e habilidade em relação à construção e utilização dos blogs. É muito comum no cotidiano da sala de aula, seja no EF ou no EM, constatar que vários estudantes postam informações, fazem comentários, aprendem e discutem sobre temas de seus interesses. Então é importante que se aproveite esse meio de comunicação e de troca de informações como uma ferramenta no apoio e na complementação do processo ensino-aprendizagem de física. Silva (2012) realizou um trabalho onde apresentou e discutiu as teorias e metodologias relacionadas à elaboração de materiais didáticos utilizando recursos computacionais. Nesse trabalho a autora explorou abordagens do tipo hipermídia, isto é, a colocação de diferentes tipos de mídia (animações, hipertextos, simulações, gráficos etc.) em um único ambiente computacional. Ela concluiu que esses materiais, colocados dessa forma, se mostram interessantes e úteis nas aplicações didáticas para o ensino de física, viabilizando uma aprendizagem mais efetiva e valorizando as diferentes formas de apresentação de um dado tópico aos estudantes. Ela ainda destaca que a hipermídia, aí se incluem os blogs e sites, constitui-se como uma rica fonte para a investigação no que tange à visualização no ensino de ciências.

Em relação às disciplinas introdutórias de cursos superiores, segundo Daniels (2010), a utilização de blogs se mostrou como uma excelente ferramenta facilitadora para que os estudantes expressassem suas próprias ideias, melhorando assim o engajamento dos mesmos. Ainda nesse sentido, Gutierrez (2005) cita que o blog tem como uma de suas características a contribuição no processo de transformar o estudante, em seu processo de aprendizado, de mero ente passivo em autor. Ainda em relação ao uso do blog no ensino, Lemos e Padilha (2013) constataram, embora no contexto do ensino superior, que o blog promove um volume maior de condutas de autor por parte do docente e, aos estudantes, permite expor seus pontos de vista pessoais.

Uma possível limitação no uso de blogs no ensino refere-se às habilidades docentes em utilizá-lo. Tanto Cortela e Nardi (2004) como Pontes e Castro (2011) indicam a necessidade de capacitação dos docentes no sentido de uma adequada apropriação dos recursos tecnológicos disponíveis. Sendo assim, é preciso que os cursos de formação de professores, em seus diferentes níveis, atentem para uma boa medida de componentes curriculares e atividades relacionadas às TIC aplicadas ao ensino. 
Outra questão importante e que também deve ser considerada na construção de blogs para o ensino é o acesso móvel. Um estudo realizado na Turquia por Gökalp (2013), envolvendo usuários de produtos educacionais disponibilizados via internet, observou que a maioria dos acessos aos conteúdos se dá através de dispositivos móveis, evidenciando a necessidade de, ao se desenvolver tal material, levar em consideração a necessidade de adequação para essa forma de acesso. Ele ainda relata a necessidade da utilização de materiais atrativos tanto a estudantes do sexo masculino assim como para aqueles do sexo feminino, isto é, que se evitem temas de interesse exclusivo de um ou de outro grupo.

Neste trabalho desenvolvemos, junto a um grupo de estudantes do $2^{\circ}$ ano do EM da rede privada de ensino, um blog com conteúdos relacionados à Lua e suas propriedades físicas. Em seguida, utilizamos tal blog junto a 8 turmas dos 3 anos do EM, com um total de 4 professores, das redes pública e privada em diferentes cidades do Estado de São Paulo. A partir de conversas com os estudantes, de um teste aplicado e dos relatos dos docentes envolvidos no trabalho, tecemos nossas considerações e conclusões sobre o uso do blog como elemento coadjuvante no ensino dos tópicos relacionados à Lua.

\section{Fundamentação}

Jerome Bruner, em sua teoria cognitiva, reconhece que é possível ensinar um determinado assunto a qualquer criança desde que se respeite o estágio de desenvolvimento em que ela se encontra. Ensinar certo tema a uma criança é transpor a estrutura de tal tema, sempre levando em consideração a visão que o aprendiz tem do mundo que o rodeia. Quando o estudante evoluir ou mudar de estágio, aprofunda-se o assunto ou o conteúdo abordado, dando continuidade ao processo de aprendizagem durante todas as etapas de seu desenvolvimento intelectual, isto é, o currículo em espiral. Uma teoria de ensino, para Bruner (1973), deve ser capaz de auxiliar no desenvolvimento intelectual, possibilitando a absorção de eventos e capacitando o indivíduo para lidar com as possíveis alternativas que eventualmente possam surgir no processo de aprendizagem.

Nessa perspectiva, a utilização das TIC, mais precisamente sites e blogs na internet, no ensino de física é um fator que possibilita novas abordagens, fazendo com que um assunto possa ser retomado de maneira mais atraente para a criança ou adolescente e, inclusive, permitindo aprofundamentos. Além disso, dadas as diferentes formas de abordagem de um dado tema por diferentes "autores digitais" nos mais variados canais, ficam garantidas as diferentes alternativas de abordagem e discussões do assunto.

A utilização de elementos digitais no ensino de física, tais como hipertextos, sites e blogs, nada mais é do que se apropriar de algo que já é parte integrante do dia a dia e, embora virtual, do ambiente do estudante. Nesse sentido, o instrumento abordado neste trabalho, o blog, se caracteriza como ferramenta que pode permitir abordagens através de diferentes pontos da teoria de Bruner. Por exemplo, o blog é uma ferramenta que possibilita a absorção de eventos em sistemas de armazenamento relacionados ao meio ambiente do indivíduo. Além disso, 
permite o desenvolvimento de habilidades em lidar simultaneamente com múltiplas alternativas de um dado tema. Outro aspecto importante é o fato de que a não linearidade permitida pelo blog pode induzir e estimular a curiosidade por parte do estudante na retomada de temas. Isso pode conduzir a uma postura mais ativa.

Ainda segundo Bruner, os conteúdos que o indivíduo deve vir a conhecer devem ser apresentados na forma de problemas, relações e lacunas a serem preenchidas pelo próprio aprendiz. Tudo isso permite que a aprendizagem apresente maior relevância ao estudante e seja mais significativa. Assim, os dispositivos virtuais como os sites, blogs, redes sociais etc., se bem aplicados, podem prestar um bom serviço ao processo de ensino-aprendizagem. Na frase anterior quando, novamente, nos preocupamos com a boa aplicação desses recursos, nos referimos ao fundamental papel do professor no sentido de guiar, orientar e supervisionar o estudante, evitando uma aprendizagem mecânica e não significativa.

Bruner (1979) aborda em um de seus livros o quão importante é a criatividade na construção do conhecimento, destacando a importância da descoberta neste processo. Nessa abordagem ele também joga luz sobre a relação entre o conhecimento e a ação do indivíduo que aprende. Assim, a construção e utilização do blog deve se relacionar a uma crítica de Bruner sobre metodologias expositivas. Ele afirma que a aprendizagem das ciências ocorre de maneira mais efetiva quando se promove o envolvimento dos estudantes no processo de descoberta e utilizando as metodologias próprias de cada ciência. Como defende Bruner (1965) em um artigo na American Psychologist, deve ser dada ao aprendiz, ainda em tenra idade, a chance de resolver problemas, conjecturar e discutir sobre sua essência.

Em relação ao uso de internet no ensino, como defende Moran (2010), ser um educador vale a pena somente se nos enquadramos num contexto de comunicação efetiva e interativa. Ele aponta a importância de se ensinar de forma não autoritária indicando, assim, a necessidade de uma mudança de postura e de atitude por parte dos professores que, por sua vez, devem apropriar-se de um novo jeito de se ensinar. Ainda segundo esse autor, o advento da internet nos coloca em uma situação na qual precisamos mudar nossas formas de aprender e ensinar. Ele conclui que o ensino através de novos meios massivos exige que mudemos a concepção de professores e estudantes, respectivamente, acerca do ato de ensinar e aprender, é necessária uma mudança de paradigmas.

Moran, Masetto e Behrens (2013) também defendem que o professor deve evitar fornecer as respostas prontas e acabadas aos seus estudantes. Ele deve, na verdade, promover a pesquisa e instigar o estudante a procurar por soluções e respostas, avançando gradativamente no grau de dificuldade e/ou profundidade de um dado tema. Os autores ainda apontam para o caráter dinâmico do blog que permite ao professor a constante atualização dos conteúdos e informações disponibilizados. 


\section{Metodologia}

Este trabalho se caracteriza como um estudo de caso e nossa abordagem ocorreu em duas diferentes, porém complementares, etapas. A primeira delas se deu junto a uma turma do $2^{\circ}$ ano do EM de uma escola da rede privada de ensino e envolveu a construção de um blog intitulado "Blog da Lua". Nesse blog, os estudantes publicaram online itens e temas relacionados ao satélite natural de nosso planeta, a Lua. Na segunda e mais ampla etapa, o blog foi utilizado junto a estudantes do EM tanto da rede pública como da rede privada, em abordagens visando o ensino de temas relacionados à Lua, cada qual respeitando os respectivos conteúdos programáticos das turmas. Descrevemos a seguir a metodologia de trabalho empregada nessas duas etapas.

\section{Construindo o Blog da Lua}

A construção do blog se deu junto a um grupo de estudantes do $2^{\circ}$ ano do EM de uma escola da rede privada de ensino da região administrativa de Campinas, no interior do estado de São Paulo. As atividades relacionadas à construção (pesquisa de material, discussões acerca dos temas, composições dos textos e imagens, publicação online do material aprovado etc.) ocorreram no contra turno (neste caso, no período da tarde) em reuniões entre o professor de física da turma e os estudantes que aderiram ao projeto proposto. Tal atividade se caracterizou como uma atividade extra e não obrigatória.

Foi dada aos estudantes ampla autonomia para se organizarem em grupos e para a escolha do tema que iriam se dedicar, desde que relacionado à Lua. Um dos grupos ficou responsável pela construção do blog efetivamente, além de definir o endereço eletrônico a ser utilizado e o local de hospedagem, este último gratuito. Os demais grupos se responsabilizaram pela determinação, obtenção e análise dos conteúdos a serem publicados. Após ampla análise e discussões entre os estudantes, sempre orientados e mediados pelo professor, ficou decidido que os conteúdos pertinentes seriam: características físicas da Lua; simuladores virtuais; curiosidades; fases e eclipses lunares; o processo de formação da Lua e como fazer uma luneta rudimentar, este último por iniciativa dos próprios estudantes. As fontes de tais conteúdos foram livros, sites na internet, artigos de divulgação e revistas.

Aos estudantes também foi delegada a tarefa de, após análise prévia, apresentar o material a ser publicado aos demais integrantes da turma. Esse momento serviu para que os estudantes fizessem uma exposição daquilo que haviam coletado e argumentassem sobre sua relevância para o blog. Coube ao docente a tarefa de auxiliar os estudantes na escolha do melhor material, na correta citação das fontes, nos ajustes referentes à escrita do texto e na composição e/ou edição de imagens. Uma vez já envolvidos com a proposta do trabalho, ocorreu a alguns dos estudantes o despertar do interesse em construir uma luneta simples. Após a confecção da luneta, os envolvidos prepararam um roteiro com a lista de materiais e os procedimentos necessários para sua construção. O aspecto gráfico do blog também foi decidido pelos 
estudantes seguindo a orientação do professor para que não ocorressem exageros gráficos e visuais que poderiam tirar o foco do conteúdo.

Boa parte dos trabalhos se deu no laboratório de informática da escola. Nele os estudantes se reuniam para realizar as pesquisas relativas aos tópicos que lhe haviam sidos delegados. Nessa etapa novamente o professor teve papel fundamental, ajudando cada um dos grupos na seleção dos conteúdos, sempre mostrando as fontes confiáveis e apresentando as razões de exclusão ou necessidade de síntese de alguns tópicos, sempre com o objetivo de melhor adequação ao canal de publicação. Ainda sob a orientação e supervisão do professor, cada um dos grupos fez a devida adaptação do material que seria utilizado no blog, transpondoos para uma linguagem mais acessível ao público esperado. Alguns grupos optaram por uma abordagem mais conceitual e menos matematizada, alegando que, caso contrário, o conteúdo poderia se tornar menos interessante.

Todos os conteúdos trabalhados pelo professor junto aos estudantes no processo de construção do blog foram delimitados pelos temas estruturadores 3 e 6 , este último com maior profundidade, do $\mathrm{PCN}^{5}$ (BRASIL, 2002). Isso se deu com o intuito de evitar desvios em relação ao tema proposto e em relação à aderência do trabalho dos estudantes ao programa da disciplina.

Na tabela 1 apresentamos um resumo com o número de estudantes envolvidos na construção de cada uma das abas do blog bem como uma breve descrição de suas atividades e/ou conteúdos. Nessa tabela, em sua $4^{\text {a }}$ coluna, também apresentamos a relação que o tema de cada uma das abas tem com o PCN+ (BRASIL, 2002), mais precisamente com os temas estruturadores 3 e 6 desse documento.

Tabela 1 - Resumo do conteúdo de cada uma das abas do blog, respectivo número de estudantes envolvidos no desenvolvimento de cada uma delas e suas relações com o PCN+.

\begin{tabular}{|l|l|c|l|}
\hline Item & $\begin{array}{l}\text { Atividade e/ou descrição dos conteúdos } \\
\text { das abas }\end{array}$ & $\begin{array}{l}\mathbf{N}^{\circ} \text { de estu- } \\
\text { dantes }\end{array}$ & $\begin{array}{l}\text { Relação } \\
\text { PCN+ com } \\
\text { 2002) }\end{array}$ \\
\hline $\begin{array}{l}\text { Construção do } \\
\text { blog }\end{array}$ & $\begin{array}{l}\text { Definição do local de hospedagem, prepara- } \\
\text { ção dos arquivos fonte e publicação online. }\end{array}$ & 2 & $\begin{array}{l}\text { Tema 3, unidade te- } \\
\text { mática 4. }\end{array}$ \\
\hline $\begin{array}{l}\text { Características } \\
\text { físicas }\end{array}$ & $\begin{array}{l}\text { Principais grandezas físicas da Lua tais } \\
\text { como massa, distância à Terra, raio, acelera- } \\
\text { ção da gravidade etc. }\end{array}$ & 6 & $\begin{array}{l}\text { Tema 6, unidade te- } \\
\text { mática 2. }\end{array}$ \\
\hline $\begin{array}{l}\text { Simuladores e } \\
\text { jogos }\end{array}$ & $\begin{array}{l}\text { Aplicações interativas para entender os fenô- } \\
\text { menos relacionados à Lua. }\end{array}$ & 5 & $\begin{array}{l}\text { Tema 6, unidade te- } \\
\text { mática 3. }\end{array}$ \\
\hline Curiosidades & Lendas, mitos e sabedoria popular. & 6 & $\begin{array}{l}\text { Tema 6, unidade te- } \\
\text { mática 3. }\end{array}$ \\
\hline
\end{tabular}

\footnotetext{
5 Documento do Ministério da Educação constituído de orientações educacionais complementares aos Parâmetros Curriculares Nacionais que trazem as referências básicas para construção das matrizes de referência.
} 


\begin{tabular}{|l|l|c|l|}
\hline Fases e eclipses & $\begin{array}{l}\text { Descrição do funcionamento, como e } \\
\text { quando ocorrem as estações do ano. }\end{array}$ & 4 & $\begin{array}{l}\text { Tema 6, unidade te- } \\
\text { mática 1. }\end{array}$ \\
\hline $\begin{array}{l}\text { Formação da } \\
\text { Lua }\end{array}$ & Teorias científicas sobre a formação da Lua. & 5 & $\begin{array}{l}\text { Tema 6, unidade te- } \\
\text { mática 2. }\end{array}$ \\
\hline $\begin{array}{l}\text { Construção de } \\
\text { uma luneta }\end{array}$ & $\begin{array}{l}\text { Passo a passo da construção de uma luneta } \\
\text { simples utilizando materiais de baixo custo. }\end{array}$ & 4 & $\begin{array}{l}\text { Tema 6, unidade te- } \\
\text { mática 2 e Tema 3, } \\
\text { unidade temática 2. }\end{array}$ \\
\hline
\end{tabular}

Na Fig. 1 apresentamos uma ilustração da tela inicial do blog da Lua que pode ser acessado em <www.oblogdalua.tumblr.com $>^{6}$. Nela podemos observar, à esquerda, os links para acesso às diferentes abas que constituem o blog.

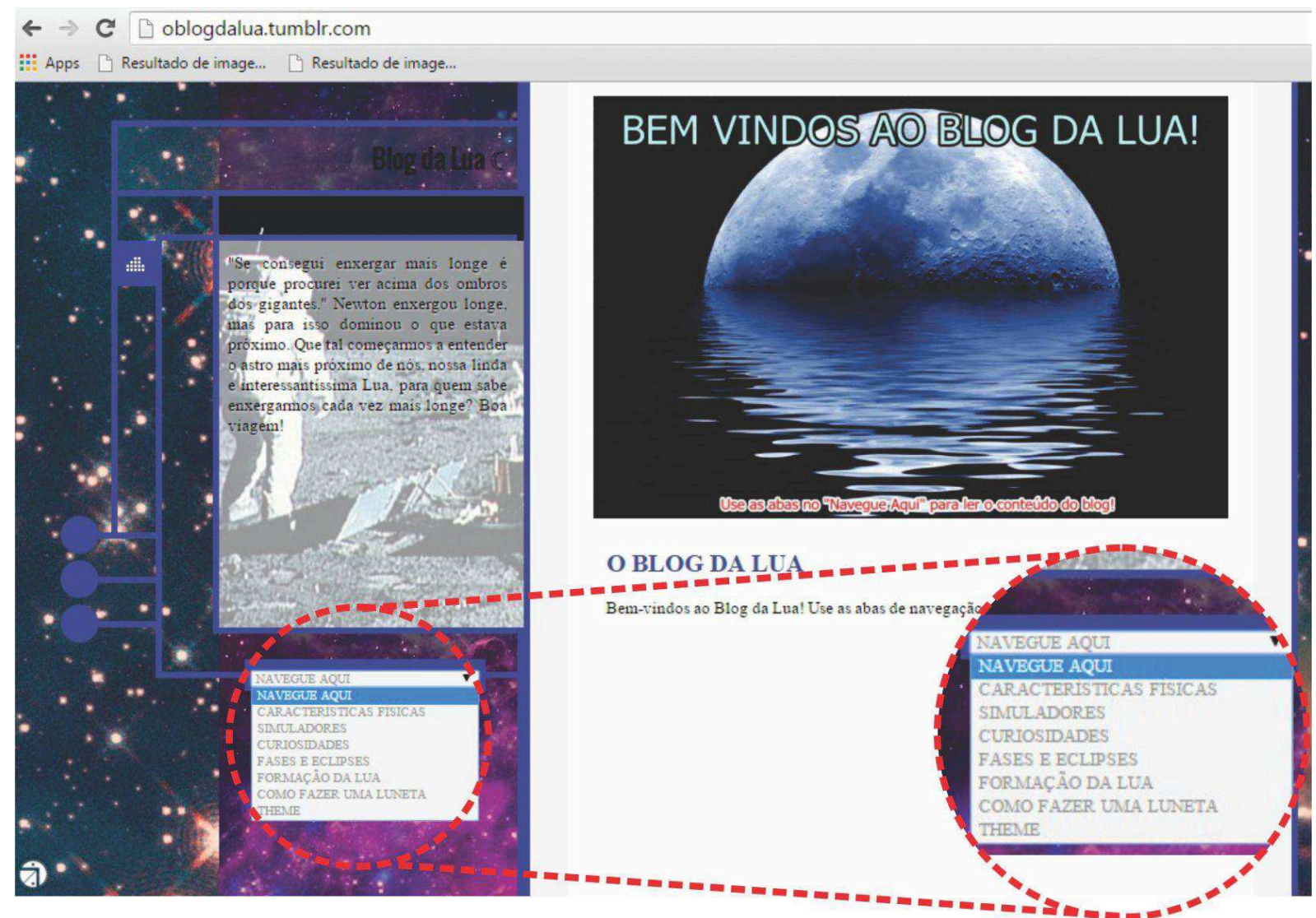

Fig. 1 - Imagem da tela inicial do blog. À direita e acima vemos uma frase de boasvindas e na parte inferior esquerda estão disponíveis os hiperlinks de navegação onde é possível ver: características físicas, simuladores, curiosidades, fases e eclipses, formação da Lua e como fazer uma luneta. No canto inferior direito, para melhor visualização, é mostrada uma ampliação da aba de navegação.

\footnotetext{
${ }^{6}$ Acesso em: 10 de outubro de 2015.
} 


\section{Utilizando o Blog da Lua}

Após o blog finalizado, o link de acesso ao mesmo foi compartilhado com outros três professores de física, tanto da rede pública como da rede privada de ensino, que o utilizaram em suas aulas dos temas relacionados à Lua. Tais professores, somados àquele que conduziu os estudantes na construção do blog, atuam em diferentes cidades também do interior do estado de São Paulo (regiões administrativas de Bauru, Botucatu, Campinas e Sorocaba).

Procuramos assegurar a uniformidade nas abordagens realizadas pelos diferentes professores na utilização do blog junto a suas turmas. Tal uniformidade teve como objetivo garantir condições de comparação entre os resultados, embora qualitativos, obtidos nas diferentes turmas envolvidas. Nesse sentido, primeiramente cada um dos professores utilizou uma aula de 50 minutos para apresentar o blog aos seus estudantes do EM, deixando um tempo para que eles pudessem explorá-lo livremente, inteirando-se de seu conteúdo. Na aula seguinte, também de 50 minutos, consultando o conteúdo do blog, os estudantes responderam a um teste, apresentado no anexo A, constituído de dez itens previamente selecionados e acordados entre os professores. Com esse procedimento, procuramos estimular os estudantes a pesquisar e descobrir as soluções aos problemas a eles colocados através do teste.

Apesar da uniformidade nas abordagens de cada um dos professores junto às suas turmas, dado o número de estudantes envolvidos e ao fato de não termos trabalhado com turmas de controle, aqui optamos por uma análise qualitativa dos dados obtidos no teste aplicado.

Com o objetivo de verificar a eficiência dessa ferramenta tecnológico-pedagógica e sua eventual eficácia no processo de ensino-aprendizagem do tema aqui abordado, o questionário foi delineado buscando abranger todas as abas do blog e, consequentemente, todo seu conteúdo. Algumas perguntas direcionavam o estudante a visualizar vídeos, ler o conteúdo de uma dada aba e explorar um simulador ou jogo. Procuramos verificar se a aprendizagem é mais efetiva e se a participação do estudante passa a ser mais ativa caracterizando, assim, o uso do blog como um dos elementos compositores de motivação intrínseca pois, como defende Bruner, nesse contexto a aprendizagem é mais duradoura.

O teste foi composto por questões da Olimpíada Brasileira de Astronomia e Astronáutica (OBA), de uma prova da Universidade Federal do Rio de Janeiro (UFRJ) e de questões criadas pelo professor que participou do processo de construção do Blog, baseando-se no tema estruturador 6 (Universo, Terra e vida) do PCN+ (BRASIL, 2002). Embora o conteúdo do blog seja suficiente para que todas as questões do teste fossem devidamente respondidas pelos estudantes, eles tiveram plena liberdade para, eventualmente, acessar links externos ao blog da Lua para compor a resolução do teste. Esse procedimento teve como objetivo permitir, àqueles estudantes que o desejassem, aprofundar seus estudos sobre pontos que julgassem ser de seu interesse. Tal atividade foi incorporada como um dos instrumentos de avaliação da disciplina por todos os professores participantes. 
Em seguida, os testes foram conjuntamente analisados com os professores com o objetivo de levantar observações e conclusões qualitativas acerca da influência da abordagem dada (apresentação prévia do blog seguida de atividade assistida pelo blog) às respostas e, consequentemente, aprendizado do tema por parte dos estudantes. Nesse momento de análise foram considerados os itens: respostas satisfatórias aos itens do teste; concentração e efetiva participação dos estudantes nas duas aulas e interação entre o estudante e o professor no contexto do problema.

\section{Discussão dos resultados}

Dado o contexto deste estudo de caso - pequeno número de turmas envolvidas, apenas um tópico trabalhado usando o blog como ferramenta auxiliar ao processo de ensino e concentração das turmas numa dada região geográfica - nossas análises limitar-se-ão a uma abordagem qualitativa.

Especificamente em relação à turma do $2^{\circ}$ ano do EM responsável pela construção do blog, o professor relatou que o contato diário e a troca de ideias, com os demais colegas de turma e com o professor, fez com que os estudantes se comportassem mais efetivamente como sujeitos ativos no processo de aprendizagem do tema. Ainda segundo o professor, observou-se um distanciamento da postura passiva dos estudantes, comumente observada quando o tema é a física. Observou-se também que estudantes até então apáticos em relação a aprender física apresentaram uma mudança de postura bastante positiva. Nesse sentido, vemos que a afirmação de Bruner de que é possível ensinar tudo a uma criança, desde que se respeite seu estágio de desenvolvimento e que sua curiosidade seja ativada, se encaixou bem neste trabalho, já que os estudantes se interessam e já apresentam um estágio satisfatório quando se fala em uso das tecnologias da informação. O professor ainda relatou que, devido à autonomia dada aos estudantes para pesquisar sobre o tema em diversas fontes, criou-se um ambiente de discussão e troca de informações sobre os materiais utilizados, sua formatação e que partes deveriam ser retiradas ou adaptadas antes de se publicar o material no blog. Neste caso, percebemos evidências de que os estudantes passaram a se comportar como co-autores de seu aprendizado, demonstrando um papel mais ativo no processo de ensino-aprendizagem em comparação, feita pelo próprio professor envolvido nesta etapa do trabalho, com turmas de anos anteriores quando se abordou o mesmo tema.

Outro ponto importante, ainda na etapa de construção do blog, se relaciona com a postura que alguns grupos apresentaram no sentido de fazer uma abordagem de seu tema do ponto de vista mais conceitual. Por exemplo, na aba "características físicas", ao abordar o tema relacionado ao tamanho da Lua, ao invés de cálculos ou mesmo tabelas contendo informações numéricas sobre as dimensões dos astros, optou-se pela indicação de um link para um vídeo que permite fazer uma comparação visual e dinâmica entre os tamanhos da Lua, planetas e estrelas. Já na aba "fases e eclipses", além de um link para uma simulação sobre as fases da Lua, foram explorados alguns elementos numéricos como, por exemplo, a duração dos eclipses 
solar e lunar. Essa postura dos estudantes nos deixou em alerta sobre a necessidade de uma menor matematização de alguns temas no sentido de aumentar a atratividade inicial aos estudantes. Embora, em alguns casos, isso exija uma simplificação na abordagem de alguns tópicos, não faz com que se perca a generalidade e sua completude conceitual. Ao contrário, essa abordagem menos matematizada, no blog, pode servir como ponto de partida para a fenomenologia do tema. Essa primeira apresentação do fenômeno, em abordagens posteriores, pode permitir aprofundamento e a consequente e, em muitos casos, indispensável matematização.

Já considerando todas as turmas envolvidas neste trabalho, segundo relatos dos professores, o blog colaborou com o despertar da curiosidade dos estudantes bem como permitiu ampla autonomia dos mesmos em relação a que tema dar maior atenção, respeitando novamente a proposta de Bruner. Desta forma, observamos que o ensino do tema aqui abordado se uniu naturalmente à tecnologia, no ritmo e interesse do estudante, promovendo maior motivação e disposição ao estudo. Dado que elementos relacionados à internet fazem parte do seu cotidiano e despertam seu interesse, como relatado por todos os professores envolvidos, ficou evidente uma motivação intrínseca no processo de aprendizagem do tema. Ainda relacionado a esse interesse natural que os estudantes têm para com a internet, neste trabalho percebemos o surgir de uma "ponte" entre estudante e professor que levou a, como relataram os professores, uma melhor interação entre os atores. A melhor comunicação entre estudantes e professores ficou evidente, concordando com proposta de Moran (2010) já mencionada na seção IV deste trabalho.

Em relação ao teste aplicado, de uma maneira geral, as respostas dadas pelos estudantes se mostraram bastante consistentes e satisfatórias, evidenciando que a organização dos tópicos e a objetividade do blog colaboram positivamente no processo de aprendizado do tema.

A Fig. 2 ilustra outra situação típica das repostas obtidas dos estudantes. Ela mostra uma reprodução da questão 3 que trata das dimensões da Lua bem como a forma correta de representação das grandezas envolvidas. No item (a) dessa questão foi solicitado ao estudante que, a partir das informações contidas na aba "características físicas", procedesse com a transformação de algumas unidades de medida. Tais unidades relacionam-se com as grandezas volume, distância, temperatura, período de rotação e massa. Além disso, no item (b) a questão aborda a representação de tais grandezas em notação científica. No item (c) é solicitado que se assista a um vídeo que trata das dimensões (tamanho) da Lua frente a outros astros. 
a)Passe o volume, a distância a Terra, a temperatura média e o período de rotação para o

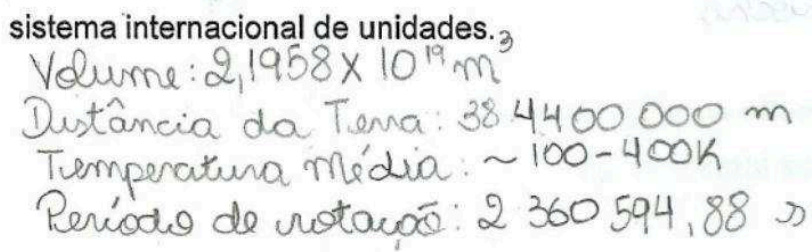

b)Escreva a massa da Lua e seu raio equatorial em notaçăo científica Marra do Lua: $7,349 \times 10^{22} \mathrm{Kg}$ Rair equationial: 1,7381 $\times 10^{3} \mathrm{~km}$

c)Abaixo da tabela das características há um link para um vídeo que compara a lua com outros astros. Acesse-o e escreva qual o maior planeta do sistema solar e também qual o nome da maior estrela conhecida e sua distância a Terra, em anos-luz. Cỡ maion, a tou- 4800 anos-luz. Júpiter.

Fig. 2 - Reprodução de uma situação típica referente às respostas apresentadas pelos estudantes para a questão número 3 do teste aplicado.

Como podemos observar, nas respostas dada à questão 3 é possível perceber a compreensão do estudante sobre o tema bem como suas habilidades no processo de conversão entre diferentes unidades e representação em notação científica. Em relação ao tamanho da Lua, percebe-se que o estudante pôde ir além do tema Lua ao comparar seu tamanho com o de uma estrela gigante vermelha. Isso permitiu, como relataram os professores envolvidos neste trabalho, manifestações dos estudantes em relação a quão pequena é a Lua frente ao Universo. Além disso, embora no contexto do estudo da Lua as distâncias possam ser adequadamente representadas em metros ou em quilômetros, a comparação com a gigante vermelha permitiu explorar o conceito de ano-luz, unidade de medida indispensável quando se trata de astros mais distantes da Terra.

A Fig. 3 reproduz uma resposta típica obtida neste trabalho para as questões 4 e 5 do teste aplicado. Essas duas questões trabalharam de forma conjunta. Na questão 4 é solicitado ao estudante que, ao ler o texto "eternos namorados" disponível na aba "curiosidades", conclua sobre o fenômeno físico relacionado ao sistema Sol-Terra-Lua a que se refere o trecho "...o Sol se deita sobre a Lua e começam a se amar...”. Como podemos observar na resposta dada à questão 4, os estudantes concluíram tratar-se do eclipse. Embora na resposta à questão $4 \mathrm{o}$ estudante tenha citado ambos os eclipses, na resposta dada à questão 5 ficou evidenciada a conclusão de que se trata de um eclipse solar. 


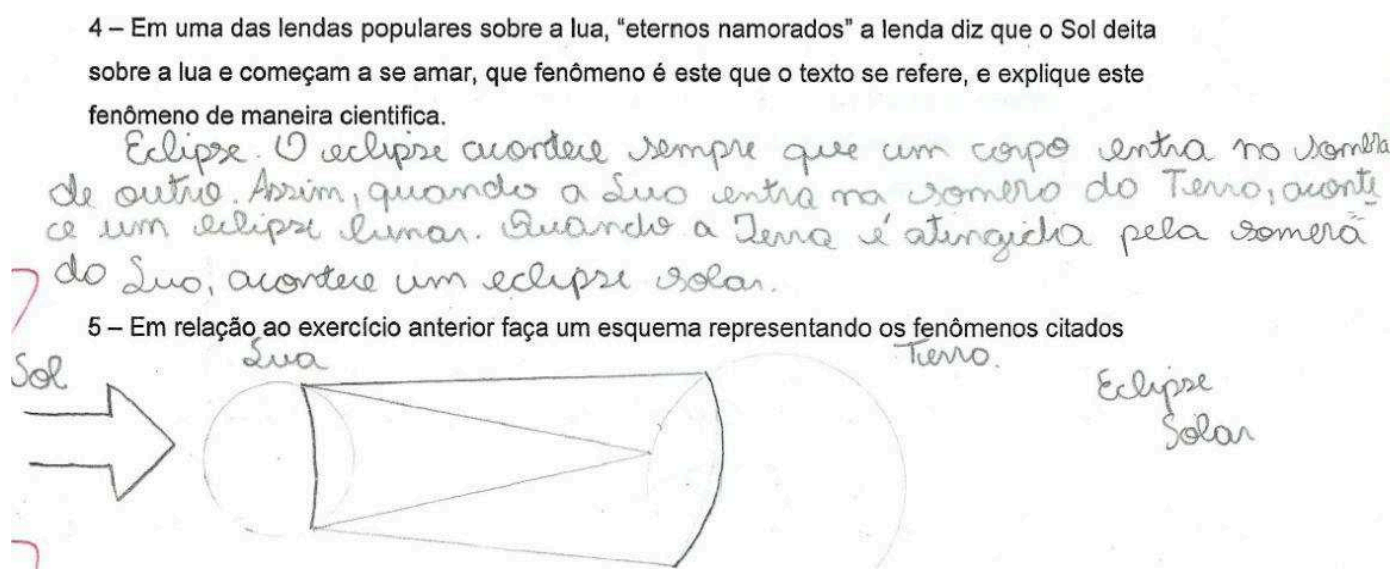

Fig. 3 - Reprodução de uma situação típica referente às respostas apresentadas pelos estudantes para a questão números 4 e 5 do teste aplicado.

Ainda na resposta dada à questão 4, o estudante também demonstrou compreender que o eclipse lunar ocorre quando a Lua, em sua totalidade ou parcialmente, se encontra sob a sombra da Terra, ficando assim ocultada em relação ao Sol.

Outro ponto importante é que, de maneira geral, ficou claro o aprendizado demonstrado pelos estudantes em relação às fases da Lua, pois foi possível detectar que haviam compreendido que tais fenômenos se relacionam com o fato de que ela se move em torno da Terra. Eles demonstraram ter compreendido que as fases ocorrem devido às diferentes porções da face iluminada da Lua que está voltada para a Terra em diferentes momentos. Além disso, os estudantes recorreram com frequência a seus professores relacionando tais conhecimentos com aqueles pertinentes à sabedoria popular.

A Fig. 4 apresenta uma reprodução da questão 9 do teste aplicado bem como um exemplo de resposta dada pelos estudantes envolvidos. Essa questão, por exemplo, permitiu avaliar a compreensão dos estudantes em relação à localização dos astros, neste caso o Sol e a Lua, no firmamento. Como podemos observar nessa figura, o estudante em questão demonstrou compreender que o Sol ilumina a Lua, ou seja, que esta última não possui luz própria, e que a posição correta é aquela apresentada à esquerda. 
๑- A Lua brilha no céu porque é iluminada pelo Sol. Em alguns dias do mês, pela manhã ou a tarde, podemos ver o Sol e a Lua juntos no céu. Nos desenhos abaixo você pode ver representações FORA DE ESCALA dessa situação, onde uma está certa e a outra está errada em relação somente à iluminação. Escreva embaixo de cada desenho se está CERTO ou ERRADO.
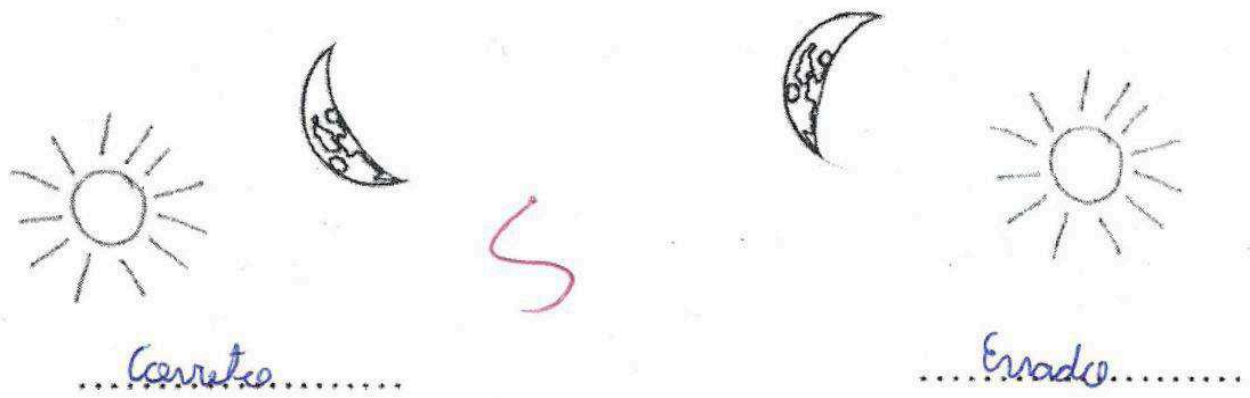

Fig. 4 - Reprodução de uma situação típica referente às respostas apresentadas pelos estudantes para a questão número 9 do teste aplicado.

No que diz respeito ao esforço docente, como relataram os professores envolvidos, não houve um aporte excessivo de trabalho. Dada a familiaridade que os estudantes já possuíam em relação ao uso do computador e da internet, todos os professores relataram que os trabalhos transcorreram de forma bastante natural. Outra vantagem, do ponto de vista do docente, é que o blog se caracteriza como um material sem "prazo de validade" dado que uma vez criado pode ser reutilizado e reaplicado ano após ano, bastando que se façam as alterações e/ou adaptações necessárias. Essa característica do blog também foi apontada por Moran e colaboradores (2013). Tal possibilidade de constante ajuste e adaptação do blog à necessidade do docente frente às suas turmas vai ao encontro também da proposta de Bruner do ensino em espiral, pois maior ou menor profundidade pode ser dada pelo professor ao conteúdo do blog.

\section{Conclusões}

Neste trabalho analisamos a influência da construção de um blog por uma turma do $2^{\circ}$ ano do EM na melhoria da motivação e qualidade do aprendizado de temas relacionados à Lua. Também observamos como sua utilização por algumas turmas também do EM, em diferentes regiões administrativas do Estado de São Paulo, implica em melhorias no processo ensinoaprendizagem.

Concluímos que a utilização do blog permitiu uma participação mais efetiva de todos os estudantes, tanto daqueles que construíram o blog assim como daqueles que apenas o utilizaram. Nas turmas envolvidas neste trabalho, isso garantiu um melhor aprendizado de acordo com os relatos dos professores envolvidos no processo e também conforme indicado nas análises das respostas dadas aos itens do teste aplicado. 
Concluímos também que o fato de abordarmos o tema através de um recurso tecnológico que é familiar e comum aos estudantes, por si só, já permitiu observar uma sensível melhora na postura e no envolvimento do estudante com o tema trabalhado. Isso evidencia a capacidade que as TIC aplicadas ao ensino têm em gerar motivação intrínseca nos estudantes. Outra observação bastante importante e que se relaciona diretamente com a teoria de Bruner é em relação aos diferentes níveis de profundidade que pôde ser dada às intervenções de cada estudante junto ao professor. Nesse sentido, o uso do blog, no contexto abordado neste trabalho, respeita o conhecimento prévio que os estudantes já trazem consigo e permite que o aprofundamento no tema seja dado de acordo com esse conhecimento. Nesse sentido, e indo ao encontro da proposta de Moran e seu colaboradores, uso do blog permite ao professor direcionar as pesquisas de seus estudantes sob a luz de seus objetivos em relação ao conteúdo programático. Partindo do blog, os estudantes têm a opção de aprofundar seus conhecimentos utilizando, por exemplo, links previamente determinados pelo professor.

A utilização do blog para o ensino de física, seja construindo ou apenas utilizando-o nas atividades didáticas em sala, colabora com o processo de transformação do conhecimento em uma ferramenta a serviço do pensar e do agir do indivíduo. Dessa forma, destacamos a importância de sua utilização, por parte dos professores de física, dos recursos oferecidos pelas tecnologias da informação de modo a aprimorar sua atuação e, consequentemente, a qualidade do ensino da física.

Apesar dos bons resultados observados neste trabalho, o uso do blog deve ser acompanhado cuidadosamente pelo professor. Isso se deve ao fato de o estudante atuar num contexto online, o que pode induzi-lo a se distrair - deliberadamente ou não - acessando outros conteúdos não pertinentes à aula. Outro fator que pode limitar os trabalhos do professor relaciona-se à existência de laboratório de informática na escola e ao acesso à internet, nem sempre disponíveis. Isso traria prejuízos tanto na construção como na utilização do blog durante as aulas. Um contexto desses, provavelmente, faria com que o blog apresentasse uma contribuição reduzida, pois os estudantes só poderiam utilizá-lo fora da escola e, assim, sem o acompanhamento e orientação - em tempo real - do professor.

\section{Referências}

ARAUJO, I. S.; VEIT, E. A.; MOREIRA, M. A. Modelos computacionais no ensinoaprendizagem de Física: um referencial de trabalho. Investigações em Ensino de Ciências, v. 17, n. 2, p. 341-366, 2012.

BRASIL, M. D. E. PCN+ Ensino médio: orientações educacionais complementares aos Parâmetros Curriculares Nacionais - Ciências da Natureza, Matemática e suas Tecnologias. Brasília: MEC/Semtec, 2002. 
BRASIL, M. D. E. Diretrizes Curriculares Nacionais Gerais da Educação Básica. Brasília: MEC, 2013. v. único.

BRUNER, J. S. The growth of mind. American Psychologist, v. 20, p. 1007-1017, 1965.

BRUNER, J. S. O Processo da Educação. São Paulo: Nacional, 1973.

BRUNER, J. S. On Knowing: Essays for the Left Hand. Londres: Belknap Press, 1979.

CORTELA, B. S. C.; NARDI, R. Formadores de professores de Física: uma análise de seus discursos e como podem influenciar na implantação de novos currículos. In: ENCONTRO DE PESQUISA EM ENSINO DE FÍSICA, IX, 2004, Jaboticatubas, MG. Atas...

DANIELS, K. E. Student Blogging about Physics. The Physics Teacher, v. 48, p. 366-367, 2010.

DEL BARCO, E.; PAREDES, J. An interactive Science Blog at UCF for High School science students. The Physics Teacher, v. 48, p. 506-507, 2010.

DUDA, G.; GARRET, K. Blogging in the physics classroom: A research-based approach to shaping students' attitudes toward physics. American Journal of Physics, v. 76, n. 11, p. 10541065, 2008.

FIOLHAIS, C.; TRINDADE, J. Física no computador: O computador como uma ferramenta no ensino e na aprendizagem das ciências físicas. Revista Brasileira de Ensino de Física, v. 25, n. 3, p. 259-272, 2003.

FRAGA, V. M. et al. Blog como recurso didático pedagógico no ensino de ciências: as tecnologias de ensino na era dos nativos digitais. In: ENCONTRO NACIONAL DE PESQUISA EM EDUCAÇÃO EM CIÊNCIAS, 2011, Campinas. p. 1-11.

GÖKALP, M. S. Perceptions of the Internet and Education: A Study with Physics Education Website Users. International Journal of Environmental \& Science Education, v. 8, n. 2, p. 289-302, 2013.

GUTIERREZ, S. Weblogs e educação: contribuição para a construção de uma teoria. Novas Tecnologias na Educação, v. 3, n. 1, 2005.

LEITE, B. S.; CARNEIRO, M. B. A web 2.0 como ferramenta de aprendizagem no ensino de Ciências. Nuevas ideas en informática educativa, v. 5, p. 77-82, 2009.

LEMOS, L. D. L.; PADILHA, M. A. S. Interações no ensino superior através da web 2.0: uma análise das condutas geradas no blog e youtube. Revista Brasileira de Ensino de Ciências e Tecnologia, v. 6, n. 3, p. 64-81, 2013. 
MORAN, J. M. Cambiar la forma de ensenãr con internet. Aletheia, Revista de desarrollo humano, educativo y social contemporáneo, Manizales, v. 2, n. 2, p. 1-9, 2010.

MORAn, J. M.; MASETTO, M. T.; BEHREnS, M. A. Novas Tecnologias e Mediação Pedagógica. 21. ed. Campinas: Papirus, 2013. p. 36-46.

PALFREY, J.; GASSER, U. Nascidos na era digital: Entendendo a primeira geração dos nativos digitais. Porto Alegre: Artmed, 2011.

PIETROCOLA, M. Ensino de Física. Florianópolis: Editora da UFSC, 2006.

PONTES, R. L. J.; CASTRO FILHO, J. A. O uso do blog como ferramenta de ensinoaprendizagem por professores participantes do Projeto Um Computador por Aluno (UCA). In: SIMPÓSIO BRASILEIRO DE INFORMÁTICA NA EDUCAÇÃO, 2011, Aracaju. p. $1478-1487$.

SILVA, T. Um jeito de fazer hipermídia para o ensino de Física. Caderno Brasileiro de Ensino de Física, v. 29, n. Especial 2, p. 864-890, 2012.

TORRES-ZÚÑIGA, V. Blogs as an effective tool to teach and popularize physics: a case study. Latin-American Journal of Physics Education, Cidade do México, v. 3, n. 2, p. 214-220, 2009.

UNESCO. Organização das Nações Unidas para a Educação, Ciência e Cultura. UNESCO, 2015. Disponivel em: <http://www.unesco.org/new/pt/brasilia/communication-and-informati on/access-to-knowledge/ict-in-education/>. Acesso em: 21 out. 2015.

VASCONCELOS, F. C. G. C.; LEÃO, M. B. C. Utilização de recursos audiovisuais em uma estratégia FLEXQUEST sobre radioatividade. Investigações em Ensino de Ciências, v. 17, n. 1, p. 37-58, 2012.

\section{Anexo A - Teste aplicado aos estudantes}

O texto entre parênteses logo após o número de cada item indica a sua fonte. As figuras em cada um dos itens têm como fonte aquela de onde o item foi retirado.

1 - (XVII OBA 2014 - nível 3) Utilize a aba "fases e eclipses" para a próxima questão. De forma simplificada, dizemos que um eclipse do Sol ocorre quando a Lua passa na frente dele e o

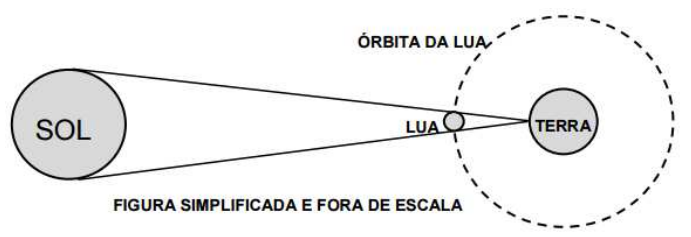
da Lua quando ela passa dentro da sombra da Terra, a qual é opaca e iluminada pelo Sol, como você sabe. Escreva $\mathbf{C}$ para certo ou $\mathbf{E}$ para errado na frente de cada afirmação abaixo:

( ) Eclipses lunares só ocorrem na Lua Cheia. 
( ) Quando os eclipses solares estão ocorrendo podem ser vistos por todos na Terra.

2 - (XVI OBA 2014 - nível 3) Aparentemente a Lua e o Sol têm o mesmo tamanho, pelo menos é o que parece quando comparamos os dois lá no céu, mas isso porque a Lua está muito mais próxima da Terra.

a) Sabemos que o diâmetro aproximado da Terra é 12.756

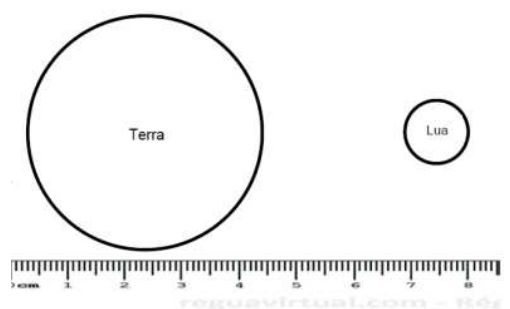
$\mathrm{km}$ e o da Lua é de $3.476 \mathrm{~km}$. Usamos estes dados para fazer a figura ao lado. Quantas vezes o diâmetro da Terra é maior do que o da Lua? Se preferir, use a régua ao lado. Abaixo há espaço para suas contas.

b) A distância entre as superfícies da Terra e da Lua é de aproximadamente $384.000 \mathrm{~km}$. Quantas Terras caberiam enfileiradas, lado a lado, entre ambas?

3 - (Elaborada pelo professor) Ao acessar o Blog da lua você encontrou suas características físicas.

a) Passe o volume, a distância da Terra, a temperatura média e o período de rotação para o sistema internacional de unidades.

b) Escreva a massa da Lua e seu raio equatorial em notação científica.

c) Abaixo da tabela das características há um link para um vídeo que compara a Lua com outros astros. Acesse-o e escreva qual o maior planeta do sistema solar e também qual o nome da maior estrela conhecida e sua distância à Terra, em anos-luz.

4 - (Elaborada pelo professor) Em uma das lendas populares sobre a Lua, "eternos namorados", é dito que o Sol deita sobre a Lua e começam a se amar. Que fenômeno é este a que o texto se refere? Explique este fenômeno de maneira científica.

5 - (Elaborada pelo professor) Em relação ao exercício anterior, faça um esquema representando os fenômenos citados.

6 - (Elaborada pelo professor) Assista ao vídeo formação da Lua e assinale a alternativa correta em relação à teoria que o vídeo aborda.

( ) Lua, irmã da Terra.

( ) Lua, filha da Terra.

( ) Lua, namorada da Terra.

( ) Lua, irmã siamesa da Terra.

7 - (Elaborada pelo professor) Na aba "simuladores", acesse o jogo "pouso lunar" e faça a nave pousar tantas vezes quanto necessário até aparecer a mensagem "POUSO SUAVE". Chame o professor assim que alcançar seu objetivo. 
8 - (Prof ${ }^{\text {a }}$. Marta F. Barroso, UFRJ - adaptada ${ }^{7}$ ) Marque com V (verdadeiro) ou F (falso). Justifique (ou dê um contra-exemplo) para todas as afirmações que você julgar falsas.

A - A Lua reflete a luz do Sol. ( )

$\mathrm{B}$ - O Sol está no céu de dia e a Lua está no céu à noite. ( )

C - Quando a Lua está cheia, a vemos com a aparência de um semicírculo. ( )

D - O Sol é do mesmo tamanho da Lua. ( )

E - A Lua apresenta sempre o mesmo aspecto no céu. ( )

F - No Brasil, é primavera entre setembro e dezembro. ( )

G - A Lua possui um "lado escuro", nunca iluminado pelo Sol. ( )

H - A Lua é um objeto iluminado, com luminosidade própria. ( )

I - A Lua gira em torno de seu eixo de forma tal que apresenta sempre a mesma face voltada para a Terra. ( )

J - Eclipses são efeitos causados pelo sombreamento da luz do Sol de regiões do espaço pela presença de um corpo celeste. ( )

K - Um eclipse lunar ocorre quando a Lua entra na parte escura da sombra da Terra. ( )

L - Eclipses lunares só ocorrem quando a Lua está na fase Nova. ( )

M - Eclipses lunares sempre ocorrem quando a Lua está na fase Cheia. ( )

9 - (XVII OBA 2014 - nível 3) A

Lua brilha no céu porque é iluminada

pelo Sol. Em alguns dias do mês, pela manhã ou à tarde, podemos ver o Sol
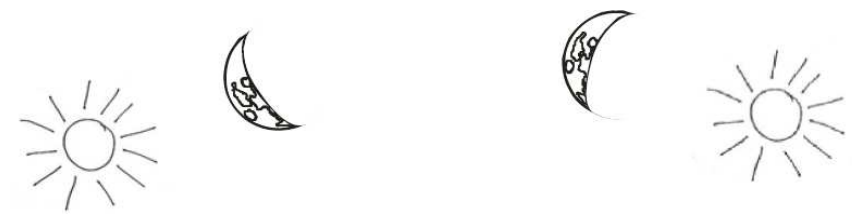

e a Lua juntos no céu. Nos desenhos

ao lado você pode ver representações dessa situação, onde uma está certa e a outra está errada em relação somente à iluminação. Escreva embaixo de cada desenho se está CERTO ou ERRADO.

10 - (XVII OBA 2014 - nível 3) No desenho abaixo, da Lua e algumas estrelas, faça um CÍRCULO sobre a única estrela de cada desenho que não poderia estar onde foi desenhada, pois nunca seria vista ali.

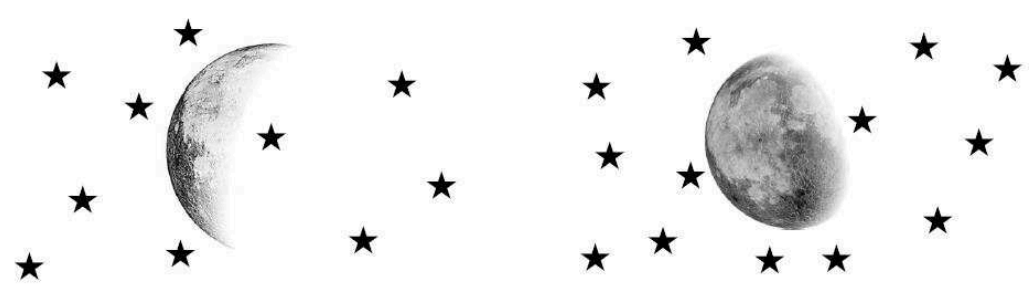

7 Obtido em <http://www.if.ufrj.br/ marta/introd-fis/unidade6-02-ex-aval-2-solucao.pdf>. Acesso em: 03 abr. 2015. 